\title{
Correction to: Synthesis, characterization, crystal structure, and antituberculosis activity of some novel polysubstituted aminocarbothiol/thiohydantoin-pyrrolidine derivatives
}

\author{
Samet Poyraz ${ }^{1} \cdot$ Samet Belveren $^{1} \cdot$ Mahmut Ülger $^{2} \cdot$ Ertan SSahin $^{3} \cdot$ \\ H. Ali Döndaş ${ }^{1}$ (i)
}

Published online: 18 January 2018

(C) Springer-Verlag GmbH Austria 2018

\section{Correction to: Monatsh Chem \\ DOI 10.1007/s00706-017-2039-0}

The original version of this article unfortunately contained a mistake. In Section "Antituberculosis activity" Table 1 should be cited instead of Table 2. And the presentation of Table 1 and of Figure legend 2 were incorrect. The corrected Table 1 and Figure legend 2 are given below.

Fig. 2 a Molecular structures of compound cis-6a; b dimers formed by effective H-bonding geometry; c stacking motif of the layers on $b c$-plane
Table 1 MIC values of target compounds against M. tuberculosis H37Rv strain

\begin{tabular}{ll}
\hline Compound & MIC values $/ \mu \mathrm{g} \mathrm{cm}^{-3}$ \\
\hline $\mathbf{5 a}$ & 125 \\
$\mathbf{5 b}$ & 62.5 \\
$\mathbf{5 c}$ & 125 \\
$\mathbf{5 d}$ & 62.5 \\
cis-6a & 125 \\
trans-6'a & 62.5 \\
6b & 62.5 \\
6c & 125 \\
6d & 62.5 \\
Isoniazid & 0.2 and 1 \\
Etambutol & 5 and 10 \\
\hline
\end{tabular}

The online version of the original article can be found under https://doi.org/10.1007/s00706-017-2039-0.

\section{H. Ali Döndaş}

yakdas25@mersin.edu.tr

1 Department of Chemistry, Faculty of Pharmacy, Mersin University, 33169 Mersin, Turkey

2 Department of Pharmaceutical Microbiology, Faculty of Pharmacy, Mersin University, 33169 Mersin, Turkey

3 Department of Chemistry, Faculty of Science, Atatürk University, 25240 Erzurum, Turkey 